\title{
UM MÉDICO SEM FRONTEIRAS: A TRAJETÓRIA DE JOFFRE MARCONDES DE REZENDE E A DEFINIÇÃO DE UMA NOVA FORMA CLÍNICA DA DOENÇA DE CHAGAS
}

\author{
A PHYSICIAN WITHOUT BORDERS: THE TRAJECTORY OF JOFFRE MARCONDES DE REZENDE AND THE DEFINITION OF \\ A NEW CLINICAL FORM OF CHAGAS DISEASE \\ Tamara Rangel Vieira* \\ tamararangel@yahoo.com.br
}

\begin{abstract}
RESUMO: o texto evidencia o processo que levou ao reconhecimento do megaesôfago como manifestação clínica da doença de Chagas - hoje plenamente aceita e enquadrada na forma digestiva da doença. A possibilidade dessa relação foi levantada pelo próprio Carlos Chagas no início do século $X X$, mas só foi retomada com força nos anos 40 pelos clínicos que atuavam no Brasil Central. Entre estes destaco Joffre Rezende, que em 1956 publicou artigo no qual a doença de Chagas foi categoricamente considerada causa do megaesôfago. Dada a relevância dessa questão no cenário médico nacional e o protagonismo de Rezende neste debate, que gerou núcleos de resistência na comunidade médica nacional, mas também aliados, sua trajetória será o fio condutor da análise que toma por base periódicos científicos, depoimentos e correspondência institucional e pessoal.
\end{abstract}

PALAVRAS-CHAVE: Doença de Chagas, Goiás, Joffre Marcondes de Rezende.

ABSTRACT: the article shows the process that led to the recognition of achalasia as a clinical manifestation of Chagas disease - fully accepted today and framed in the digestive form of the disease. The possibility of this relationship was raised by Carlos Chagas in the early twentieth century, but was only reconsidered strongly in the 40s by clinicians who worked in Central Brazil. Among these physicians, I highlight Joffre Rezende, who in 1956 published an article in which Chagas disease was considered categorically cause of achalasia. Given the importance of this issue in the national medical setting and the role of Rezende in this debate, which generated resistance groups in the national medical community, but also allies, its trajectory will conduct this analysis that takes in count scientific journals, testimonials and institutional and personal correspondence.

KEYWORDS: Chagas disease, Goiás, Joffre Marcondes de Rezende.

\footnotetext{
* Doutora em História das Ciências e da Saúde pela Casa de Oswaldo Cruz (COC)/ Fiocruz. Professora do Programa de Pós-Graduação em História das Ciências e da Saúde (PPGHCS - COC)
} 
Natural de Piumhi, interior de Minas Gerais, onde nasceu em 19 de maio de 1921, Joffre Marcondes de Rezende se formou na Faculdade Nacional de Medicina da Universidade do Brasil (atual Faculdade de Medicina da Universidade Federal do Rio de Janeiro) em 1950. Especialista em gastroenterologia, mudou-se para Goiânia em 1954 e ali desenvolveu uma carreira dedicada ao ensino, à pesquisa e à clínica, destacando-se por suas importantes contribuições ao estudo da doença de Chagas. Em depoimento concedido em 2001, Rezende conta que seguir a carreira médica era uma ideia fixa desde a infância, fruto do encantamento com que observava a postura e dedicação dos médicos que recebia em sua casa (REZENDE, 2001).

Uma vez na faculdade, teve contato com catedráticos de renome como Álvaro Osório de Almeida, Olímpio da Fonseca e Carlos Chagas Filho. ${ }^{1}$ Durante o curso, trabalhou como médico interno do Hospital Moncorvo Filho e na Maternidade Escola. Vivenciou, no período final de sua formação nos anos 50, o momento de otimismo que tomava conta da ciência após o término da II Guerra Mundial. Entrou em contato com os novos medicamentos e aparelhos que chegavam para renovar a medicina, o que, segundo Rezende, trazia um clima geral de avanço e progresso. Depois de formado, trabalhou no Pronto-Socorro do Hospital Souza Aguiar, no Rio, ao mesmo tempo em que fazia um curso de cirurgia geral para se aperfeiçoar e chegar com mais experiência até o interior do país desejo que sempre o motivou (REZENDE, 2001, fita 01/lado A). Antes de fixar residência em Goiânia, Rezende atuou por dois anos na cidade de Bela Vista, em Mato Grosso, na divisa do Brasil com o Paraguai, e voltou ao Rio para especializar-se em gastroenterologia. Chegou à cidade goiana em 1954 como primeiro médico nesta especialidade.

Em 1951 atuavam em Goiás cerca de 200 médicos, sendo que 69 deles em Goiânia e 21 deles em Anápolis. Em 28 dos 77 municípios goianos existentes não havia médico. 0 pronunciamento do Secretário de Saúde do Estado José Peixoto da Silveira no X Congresso Brasileiro de Higiene em 1953 reforçando estas estatísticas sugere que a situação em Goiânia não deveria ser muito diferente quando da chegada de Rezende à cidade um ano depois (SILVEIRA, 1981, p. 29-35). No que se refere às instituições de saúde existentes em Goiânia, além de um sanatório para tuberculosos, podemos citar a Santa Casa de Misericórdia (que em 1954 possuía um corpo médico composto por 31 profissionais) e alguns poucos hospitais e clínicas privados, como por exemplo, a Casa de Saúde Dr. Rassi e os hospitais Santa Luíza e São Lucas.

Em Goiânia, Rezende atuou em sua clínica particular, lecionou na Escola de Enfermagem São Vicente de Paulo de Goiânia (entre 1954-1955 e 1956-1965) e trabalhou

\footnotetext{
${ }^{1}$ Professores catedráticos de fisiologia teórica e experimental, parasitologia e biofísica, respectivamente.
} 
na Divisão Técnica da Secretaria de Saúde (entre 1955 e 1962). Durante sete anos atuou como médico convidado na Santa Casa de Misericórdia, onde possuía um serviço de dilatação do esôfago e fazia o atendimento gratuito à população carente. Neste período, ficou impressionado com o elevado número de pessoas que buscava seu serviço por conta do 'mal de engasgo'. O grande volume de pacientes que atendia, inclusive em seu consultório, acometidos por esta doença, o levou a conclusão de que se tratava de uma endemia.

A experiência adquirida por Rezende em função do atendimento diário a pacientes que sofriam com o problema o despertaria para as pesquisas clínicas em doença de Chagas. Tais pesquisas o levariam à associação entre a afecção, conhecida também como 'megaesôfago', e a infecção pelo Trypanossoma cruzi, configurando uma das formas possíveis de manifestação da enfermidade chagásica que ele denominaria mais tarde de 'forma digestiva'. Em conjunto com outros médicos do interior, que já vinham evidenciando a elevada quantidade de doentes de 'mal de engasgo' atendidos em seus consultórios, Rezende se destacaria por esta associação ao considerar, desde 1956, a doença de Chagas como causa do megaesôfago (REZENDE, 2009). Dada a relevância que essa questão assume no cenário médico-científico nacional, e o protagonismo de Rezende neste debate, o objetivo deste artigo é evidenciar o papel dos clínicos do interior do Brasil no processo de aceitação e reconhecimento desta nova manifestação clínica da doença de Chagas a partir da trajetória intelectual de Rezende.

Tomando por base artigos da Revista Goiana de Medicina - periódico do qual Rezende era editor - depoimentos e correspondência institucional e pessoal, realizo inicialmente um breve histórico do problema do megaesôfago, indicando também os primeiros trabalhos de médicos do interior nos quais este problema aparece associado à doença de Chagas. Em seguida, meu foco recai sobre o interesse de Rezende em aprofundar-se sobre o tema, os resultados de seus primeiros estudos e os esforços empreendidos na sua divulgação, que envolvem inclusive o intercâmbio internacional tema da terceira parte deste artigo. Por fim, destaco alguns eventos que indicam o começo da aceitação plena deste enunciado, sinalizando os últimos sinais de resistência à associação estabelecida e consolidada pelos médicos do interior do Brasil. Seguindo os passos deste gastroenterologista é possível evidenciar as redes de intercâmbio construídas pelos médicos do interior com seus pares no país e no exterior - fundamentais para a legitimidade e o reconhecimento adquirido por suas pesquisas. 


\section{Os clínicos do interior e uma nova etiologia para o 'mal de engasgo’²}

A acalásia, ou 'mal de engasgo' e 'entalação' como são popularmente conhecidos, é uma doença de caráter endêmico que acomete populações rurais de algumas regiões do Brasil e se caracteriza pela dificuldade de deglutir alimentos. Desde o final do século XIX o interesse por esta doença levou a pesquisas em torno de sua etiologia e outros nomes foram sugeridos para a enfermidade (ETZEL, 1999; REZENDE, 1998, 2001, 2009; DIAS, 2001). Teria sido o próprio Carlos Chagas o primeiro a manifestar a possibilidade da etiologia chagásica do 'mal de engasgo' em trabalho em que discorre sobre a forma aguda da tripanossomíase (CHAGAS, 1916). Tal possibilidade havia sido por ele aventada após tomar conhecimento do relatório da viagem dos médicos Arthur Neiva e Belisário Penna ao Brasil Central em 1912 (NEIVA, PENNA, 1999). Neste relatório, o 'mal de engasgo' foi descrito como um problema que acometia grande parte da população do interior do país, 'coincidentemente' habitantes das zonas em que grassava o mal de Chagas. Embora fornecendo subsídios para que Chagas desconfiasse dos vínculos entre as doenças, nenhuma suspeita neste sentido foi levantada por aqueles dois médicos.

Em texto no qual traça um histórico sobre o reconhecimento da etiologia chagásica do 'mal de engasgo', Rezende afirma que tal possibilidade nunca teria sido inteiramente afastada desde que Chagas se manifestou a respeito no início do século XX (REZENDE, 1998). Porém, a ideia teria passado por um longo período de hibernação enquanto se discutiam outras prováveis causas, só sendo retomada nos anos 40 . Entre as razões para a resistência na aceitação dos vínculos entre as duas enfermidades estavam o fato de o referido mal também ser encontrado em locais onde a doença de Chagas não existia e o medo de que se reprisasse o episódio do bócio em que, equivocadamente, se afirmou pela existência de uma forma endócrina da doença de Chagas. ${ }^{3}$ Nos anos 30 Eduardo Etzel, médico paulista, desenvolveu a teoria de que o 'mal de engasgo' ou 'megaesôfago', tal como começou a ser chamado, seria fruto da avitaminose B1 (ETZEL, 1999). Bem recebida nos meios acadêmicos, segundo Rezende, essa teoria teria retardado o reconhecimento do vínculo etiológico entre as duas doenças (REZENDE, 1956, p. 310; 1998, p. 11).

\footnotetext{
2 Nesta seção não farei uma análise minuciosa sobre o 'mal de engasgo' no âmbito da literatura médica a respeito, apenas fornecerei subsídios importantes para que seja possível compreender o cenário em que se desenvolveram os debates científicos quando os médicos do interior nele tomaram parte de modo mais incisivo.

${ }^{3}$ Antes de ser reconhecida como uma doença essencialmente cardíaca acreditou-se que a doença de Chagas também apresentaria distúrbios endócrinos, cuja manifestação mais expressiva seria o bócio. Mais tarde comprovou-se que não havia relação entre as enfermidades, apenas coincidência das áreas em que se manifestavam (KROPF, 2009).
} 
A partir do final dos anos 40 a teoria de Etzel passou a ser questionada de forma mais veemente, principalmente pelos médicos que atuavam no interior do país, nas regiões onde aquela enfermidade grassava endemicamente. Os Congressos Médicos do Triângulo Mineiro e Brasil Central ${ }^{4}$ constituíram seu principal canal de expressão e palco onde se desenrolou parte dos debates entre aqueles favoráveis à etiologia chagásica do megaesôfago endêmico - em sua maioria médicos de Goiás, Triângulo Mineiro e Ribeirão Preto - e os que se mostravam resistentes, provenientes do Rio de Janeiro e de São Paulo. Alegando principalmente superposição de áreas endêmicas e falta de comprovação anatomopatológica, insistiam estes médicos na hipótese da avitaminose (REZENDE, 1998, 2001, 2009; PRATA, 1999; KROPF, RASSI, 2009).

Em histórico traçado por Calil e Celmo Porto, médicos atuantes em Araguari, percebe-se com clareza como caminharam os debates sobre o tema do megaesôfago desde o primeiro destes congressos em 1947 (PORTO, PORTO, 1970). Foi em uma de suas edições que Rezende apresentou trabalho pelo qual ganharia reconhecimento ao confirmar a etiologia chagásica do megaesôfago. Considerado "emblema da contribuição científica dos chamados médicos do interior para os conhecimentos sobre a doença de Chagas" (KROPF, RASSI, 2009, p. 470), o trabalho 'Megaesôfago por doença de Chagas' (REZENDE, 1956) está entre os clássicos sobre o tema, figurando como tal no livro lançado pela Fundação Oswaldo Cruz em 2009 em comemoração ao centenário da descoberta da doença (CAEVALHEIRO et al., 2009). Este aspecto merece ser ressaltado pois representa o reconhecimento de grandes instituições científicas, sediadas nos centros de ciência do país, ao trabalho dos médicos do Brasil Central.

Antes de Rezende, no entanto, alguns médicos se destacaram pelas pesquisas clínicas que davam respaldo à associação entre mal de engasgo e a tripanossomíase. 0 primeiro deles foi apresentado na segunda edição do Congresso Médico do Triângulo Mineiro, realizado em Uberlândia em 1948. Na ocasião, Virgílio Mineiro, médico daquela cidade, apresentou o trabalho 'Contribuição à etiologia do megaesôfago'. Com base exclusivamente em pesquisa clínica e com uma estatística que contabilizava mais de 1500 pacientes, o autor concluiu que o megaesôfago nada teria a ver com carência nutricional, numa referência clara à teoria da avitaminose de Etzel, deixando no ar a relação com a tripanossomíase:

\footnotetext{
4 Bem pouco conhecidos no âmbito acadêmico, estes conclaves regionais começaram em 1947 e proporcionaram maior visibilidade não apenas às enfermidades que acometiam os habitantes do interior, mas também aos médicos que alia atuavam, ganhando um peso importante na projeção de seus trabalhos além dos limites do Brasil Central na medida em que reuniam médicos provenientes de vários estados (não só do interior), alguns estrangeiros, e representantes de órgãos de saúde federais (Autor, 2012; 2015).
} 
o megaesôfago não é uma doença autônoma e sim um efeito ou consequência de outra ou outras doenças, consequência esta que poderá surgir ou não, dependendo de fatores ainda desconhecidos. E, baseado neste raciocínio, tendemos a admitir ser o megaesôfago uma consequência de doença parasitária e, dentre todas elas, a mais provável, é a tripanossomíase americana (...) (MINEIRO, 1958, p. 33).

Assim como Mineiro, Calil Porto também se pautou na pesquisa clínica e a partir da observação de 23 doentes com reação Machado-Guerreiro positiva ${ }^{5}$ e distúrbios gástricos evidentes, sugeriu a existência da gastropatia chagásica, tendo em vista que não reconheceu a existência de qualquer outra etiologia para os problemas encontrados. Apresentando o trabalho 'Gastropatia Chagásica Crônica' em caráter de nota prévia durante o VII Congresso Médico do Triângulo Mineiro e Brasil Central (CMTMBC), realizado em julho de 1955 em Uberlândia, assim se manifestou:

A doença de Chagas vem nos oferecendo ângulos novos e atraentes para inquéritos e investigações. As observações clínicas que repontam de vários cantos do País (e fora dele), espraiando-se em literatura bem fundamentada, focalizam a doença sob aspectos os mais diversos e todos muito interessantes. Muitas vezes, nós que exercemos a profissão em ambiente rico desta tripanossomíase, assumimos frente a certas condições mórbidas atitudes que não parecem se apoiar em bases científicas incontroversas. É para uma destas derivações do espírito clínico que desejamos despertar as atenções do meio científico no sentido de orientarem estudos de certa forma da doença que poderão individualizar um capítulo diferente no conteúdo desta parasitose (...) (PORTO, 1955, p. 43).

Por ocasião da apresentação deste trabalho, Joffre Rezende e Isaac Barreto Ribeiro ${ }^{6}$, presentes no evento, opinaram desde então pela existência de uma forma digestiva da doença de Chagas (PORTO, PORTO, 1970, p. 129).

\footnotetext{
${ }^{5}$ Diferente da fase aguda, quando a infecção está em seu estágio inicial e há grande quantidade de parasitos na corrente sanguínea, na fase crônica esses níveis ficam abaixo dos detectáveis por meio do exame direto do sangue por microscopia. Nesse caso, o reconhecimento da doença se baseia em métodos indiretos como a reação de Machado-Guerreiro. Elaborado em 1913 por Astrogildo Machado e César Guerreiro, pesquisadores de Manguinhos, verifica se o organismo está produzindo anticorpos contra o Trypanosoma cruzi a partir de uma prova imunológica com soro sanguíneo do doente. Embora não identificasse diretamente o parasito, permitia ver seus rastros imunológicos, evidenciando a infecção pelo Trypanosoma cruzi (KROPF, 2009).

${ }^{6}$ Originário da Bahia, onde nasceu em 1924, Isaac Ribeiro se formou em 1948 pela Faculdade de Medicina de Minas Gerais, em Belo Horizonte. Depois de formado decidiu atuar no interior do Brasil, passando por algumas cidades goianas até fixar-se em Ceres, uma colônia agrícola projetada pelo governo Vargas onde grassava a tripanossomíase (Autor, 2012).
} 


\section{Joffre Marcondes de Rezende e a forma digestiva da doença de Chagas}

No seu dia-a-dia em Goiânia, tanto na Santa Casa quanto em sua clínica particular, Rezende acumulou muitos casos de pacientes que apresentavam a doença de Chagas e que também desenvolviam o megaesôfago. Atento a esta 'aparente coincidência', trabalhou em conjunto com o cardiologista Anis Rassi ${ }^{7}$, que também estava interessado na enfermidade chagásica. Segundo relatam em seus respectivos depoimentos, este trabalho em conjunto se iniciou em 1956 e se dava da seguinte forma: todo caso de 'mal de engasgo' atendido por Rezende era encaminhado a Rassi para que exames eletrocardiográficos constatassem ou não a existência de afecção cardíaca; em contrapartida, todo caso de cardiopatia era encaminhado a Rezende para que fosse realizada a radiografia do esôfago e a dilatação do órgão ${ }^{8}$ (Rezende, 2001, fita 03/lado A; Rassi, 2001, fita 03/lado B). Tendo em vista que em Goiânia só havia um laboratório particular, inviável para pacientes sem recursos, o sangue coletado era encaminhado para realização da reação Machado-Guerreiro nos laboratórios das faculdades de medicina de São Paulo ou Ribeirão Preto, com os quais obtinham colaboração. ${ }^{9}$

Entre janeiro de 1955 e junho de 1956, 170 pacientes foram acompanhados por estes médicos. A casuística que Rezende conseguiu reunir serviu de base para o trabalho 'Megaesôfago por doença de Chagas', no qual propunha uma revisão da classificação das formas clínicas da doença de Chagas e a inclusão da forma digestiva entre elas. Apresentado no VIII CMTMBC, que aconteceu em Uberaba em 1956 (Rezende, 1956), o trabalho estava em total sintonia com o que os médicos do interior já vinham apresentando nestes congressos. Pela primeira vez, no entanto, a associação entre 'mal de engasgo' e doença de Chagas era feita de forma tão categórica. Para desenvolvê-la, Rezende se apoiou nos dados epidemiológicos fornecidos pelo Departamento Nacional de Endemias Rurais, nos recursos diagnósticos disponíveis (parte das reações sorológicas

\footnotetext{
${ }^{7}$ Em 1954, depois de se formar na Faculdade Nacional de Medicina, Anis Rassi especializou-se em cardiologia na Policlínica Geral do Rio de Janeiro e, em São Paulo, fez estágios na Faculdade de Medicina da USP, no Instituto de Cardiologia Sabbado D'Ângelo e no Instituto de Cardiologia. Instalou-se definitivamente em Goiânia a partir de 1955 (RASSI, 2001).

8 Por meio desta técnica, dilata-se o esfíncter e o doente engole por gravidade, mas não recupera a coordenação (REZENDE, 2001, fita 03/lado A).

${ }^{9}$ Anis Rassi afirma que antes da colaboração destas Faculdades, se valeu do auxílio prestado pelo Instituto Oswaldo Cruz, na pessoa de Júlio Muniz (protozoologista que ao lado de Gilberto de Freitas, também pesquisador do IOC, contribuiu com seus conhecimentos para o controle da doença de Chagas, publicando importante trabalho sobre diagnóstico sorológico nos anos 40) (Cf. RASSI, 2001, fitas 01 e 03; CARVALHEIRO et al., 2009).
} 
obtida no laboratório de Carlos Borges em Goiânia e outra nos laboratórios das faculdades de medicina paulistas já mencionadas) e nas pesquisas que Fritz Koeberle desenvolvia em Ribeirão Preto.

De origem austríaca, Koeberle foi diretor do Departamento de Patologia da então recém-criada Faculdade de Medicina de Ribeirão Preto (FMRP), vinculada à USP. Seu interesse e convicção na relação entre 'mal de engasgo' e tripanossomíase o transformou em um dos principais aliados de Rezende no processo de consolidação da etiologia chagásica dos megas. ${ }^{10}$ Defensor da legitimidade das pesquisas clínicas realizadas pelos médicos do interior, em uma conferência na Sociedade de Medicina e Cirurgia de Uberaba, em abril de 1956, Koeberle assim se posicionou:

\begin{abstract}
consideramos desautorizada a condenação de um trabalho científico pelo simples fato deste ter sido baseado apenas em observações clínicas, não utilizando aparelhagem científica para apresentar uma documentação quantitativa. As observações de C. Porto, baseadas em uma experiência de vinte anos como médico no interior do Brasil, possuem o mesmo valor documentário que nossos estudos feitos através de inúmeras observações histológicas em cortes seriados e com colorações diversas. A melhor prova da veracidade desta afirmação está em que os dois métodos levaram a resultados exatamente iguais. Ao mesmo tempo, fica demonstrado que ainda em nossos dias é possível conseguir resultados novos e importantes com meios simples na atividade médica e constituirá sempre um erro subestimá-los (...) (KÖBERLE, 1956, p. 102-103).
\end{abstract}

Sua contribuição para o trabalho desenvolvido pelos goianos viria por meio da comprovação anatomopatológica da etiologia chagásica do megacólon e megaesôfago endêmicos. Embora dados clínicos, epidemiológicos e sorológicos fornecessem evidências quanto à relação etiológica entre a tripanossomíase e o megaesôfago endêmico, como vinha sendo apresentado pelos médicos do interior nos congressos do Brasil Central, era imperativo localizar o parasito nos órgãos comprometidos pela doença para comprovar tal associação. Cabe ressaltar que, desde o século XIX o laboratório funcionava como espaço privilegiado de validação do conhecimento médico e, neste contexto, a anatomia patológica se configurou como disciplina fundamental. Através das necropsias era possível enxergar o parasito e/ou as lesões a ele atribuídas em vários órgãos e sistemas orgânicos, o que dava concretude à doença. Neste sentido, Koeberle examinou uma série de esôfagos de chagásicos autopsiados numa busca exaustiva pelo parasito. Seu trabalhou

\footnotetext{
${ }^{10}$ No trabalho que publicou em 1956, referido no texto, Rezende mencionou apenas o megaesôfago por conta do maior número de casos que conseguiu reunir. No entanto, ao propor a forma digestiva da doença de Chagas, incluiu nela as demais lesões do tubo digestivo: megaduodeno, megajejuno, megaíleo, megacólon e gastropatia chagásica (Cf. REZENDE, 1956, p. 311).
} 
complementou, assim, a pesquisa essencialmente clínica de Rezende e dos demais médicos, respaldando-as. ${ }^{11}$

Além de Koeberle, importante auxílio também foi prestado pelos médicos do Departamento de Parasitologia da FMRP, entre eles Mauro Pereira Barreto e Astolpho Ferraz de Siqueira, de onde vinha a maioria das provas laboratoriais utilizadas pelos goianos. Catedrático do Departamento de Higiene e Medicina Preventiva desta mesma faculdade, José Lima Pedreira de Freitas foi outro importante colaborador e desde 1944 dedicava-se ao estudo da doença de Chagas. Tendo aperfeiçoado a técnica do complemento de Machado-Guerreiro, tornando-a mais acurada e confiável, estabeleceu em Cássia dos Coqueiros, região do interior de São Paulo, um campo permanente de pesquisa da doença em seus aspectos clínicos e epidemiológicos (KROPF, 2009). Sua importância no seio da pesquisa sobre megaesôfago deve-se, entre outras coisas, à sua tese de doutorado de 1947 na qual admitiu a plausibilidade da relação entre aquele problema e o mal chagásico (PORTO, 1970). Comentarista oficial dos trabalhos apresentados pelos goianos no VIII CMTMBC, assim se manifestou:

Foi abordado de modo tão completo o problema do megaesôfago e moléstia de Chagas e disponho de tempo curto para terminar estes comentários que dispensaria abordar este tema. Conforme o trabalho apresentado, graças aos trabalhos do Prof. Fritz Köeberle tivemos o importante argumento anatomopatológico para aceitarmos definitivamente a etiologia chagásica do megaesôfago e dos outros "megas" entre nós. Está havendo uma reação grande por parte de nossos pesquisadores para aceitar este fato como estabelecido. Por ocasião da realização dos outros Congressos do Triângulo Mineiro e do Brasil Central, este assunto foi muito debatido e a etiologia chagásica dos "megas" aparentemente saiu sempre perdendo. Estou certo de que deste ela sairá absolutamente vitoriosa, como o mostra suficientemente a argumentação aqui apresentada pelos autores (...) (FREITAS, 1956, p. 319-320).

\footnotetext{
${ }^{11}$ Após este minucioso trabalho, Koeberle se dedicou aos estudos sobre desnervação do sistema nervoso entérico na doença de Chagas, convencido de que essa era a causa da alteração do funcionamento dos órgãos. Seus enunciados encontraram muita resistência inicialmente, principalmente ao considerar que após a reprodução intracelular do parasito, localizado nas fibras musculares da parede do tubo digestivo, a célula se romperia e liberaria uma toxina lesiva aos neurônios responsáveis pela coordenação do movimento do órgão. Mais tarde abandonou essa tese e verificou-se que, na verdade, o sistema imunológico agredia o neurônio parasitado devido a uma 'semelhança imunogênica' entre parasito e neurônio (REZENDE, 2001, fitas 02 e 03). Ao longo da análise que se segue este tema não será abordado, apesar de sua riqueza e relação com o problema dos megas. Minha opção é centrar o debate na questão da aceitação da etiologia chagásica dos megas e, por isso, os estudos de Koeberle relacionados a estas pesquisas não serão aprofundados.
} 
Embora a aceitação irrestrita da etiologia chagásica dos megas ainda não fosse uma realidade neste período, já é possível notar alguns indícios deste movimento como, por exemplo, na conferência realizada por Geraldo Siffert de Paula e Silva em 1957. A convite da Associação Médica de Goiás, este renomado professor de gastroenterologia da Pontifícia Universidade Católica do Rio de Janeiro visitou Goiânia e Brasília e pronunciou três conferências, uma delas no Centro de Estudos do Hospital Juscelino Kubistchek de Oliveira, na futura capital federal. O próprio título de sua palestra já é sugestivo neste sentido:

\begin{abstract}
Escolhi o tema 'Formas Digestivas da Moléstia de Chagas' como homenagem aos denodados e beneméritos colegas do Brasil Central que muito ajudaram a repor na ordem do dia os assuntos referentes à tripanossomíase americana, relegados a injusto olvido por mais de 40 anos (...) Merecem todos os louvores os esforços despendidos pelos clínicos do Triângulo Mineiro e do Brasil Central no sentido de esclarecer a relação etiológica entre o megaesôfago e o megacólon e a tripanossomíase (...) (PAULA E SILVA, 1958, p. 57-58).
\end{abstract}

Por incentivo de Paula e Silva, Rezende se tornou sócio fundador da Sociedade Goiana de Gastroenterologia em 1957, e seu presidente no ano seguinte. No âmbito das reuniões científicas organizadas por esta sociedade, Rezende também reafirmou suas convicções e pesquisas sobre a forma digestiva da tripanossomíase. A sessão científica que promoveu ao lado de Anis Rassi em 1957, por exemplo, se assemelha muito ao trabalho sobre megaesôfago e cardiopatia que publicariam juntos em $O$ Hospital, uma das revistas mais prestigiadas do meio médico brasileiro (REZENDE; RASSI, 1958). Neste mesmo ano, ao lado de Rassi e outros cinco médicos de Goiás (Carlos Borges, Omar Carneiro, José Salum, Isaac Ribeiro e Olímpio de Paula), Rezende apresentou o trabalho 'Fase aguda da doença de Chagas - aspectos clínicos observados em 18 casos' no I Seminário Brasileiro sobre Doença de Chagas, que aconteceu na Paraíba em dezembro de 1957 por iniciativa da sociedade local de gastroenterologia e nutrição.

Este trabalho, ao lado de alguns outros apresentados na ocasião, conformaram um número especial da Revista Goiana de Medicina totalmente dedicado à doença de Chagas, publicado em 1958 (RASSI et al, 1958). A partir dele, é possível visualizar a rede intelectual na qual estavam envolvidos os médicos goianos e seus pares de Ribeirão Preto. Ao final deste artigo escrito a várias mãos, são mencionados os colegas do interior de São Paulo que vinham colaborando com a pesquisa dos goianos, entre eles Pedreira de Freitas, Köeberle e Ferraz de Siqueira. Por outro lado, esta edição especial evidencia também alguns núcleos de resistência como, por exemplo, o médico do Hospital das Clínicas da 
Faculdade de Medicina da Universidade da Bahia, Zilton Andrade, que em seu estudo se mostrou reticente quanto à forma digestiva:

A forma digestiva seria representada pelos casos de megaesôfago e megacólon endêmicos em certas áreas do Brasil. Os portadores de megas são alta percentagem de positividade para a reação de fixação do complemento para doença de Chagas e apresentam, muitas vezes, alterações eletrocardiográficas sugestivas. $O$ assunto ainda não está devidamente esclarecido, a nosso ver (....) (ANDRADE, 1958, p. 116).

Em março de 1959 Aluízio Prata, Professor de Clínica de Doenças Tropicais e Infectuosas da mesma faculdade, proferiu uma conferência na Pontifícia Universidade Católica do Rio de Janeiro e também expôs suas dúvidas com relação à associação entre os megas e a doença de Chagas:

Propositadamente, evitamos mencionar na evolução da Doença de Chagas e entre as suas complicações a existência de megas. Isto porque, além do assunto ainda apresentar aspectos controversos será motivo de trabalho que traremos ao Congresso Internacional sobre Doença de Chagas, a ser realizado em julho próximo (...) (PRATA, 1959a, p. 94-95).

Entre 1958 e 1959, Rezende apresentou e publicou trabalhos que reforçavam a existência da forma digestiva da doença de Chagas. Em outubro de 1958, por exemplo, ao lado de Kemil Lauar e Aluizio Oliveira, Rezende apresentou ao X Congresso Brasileiro de Gastroenterologia, realizado em Belo Horizonte, trabalho que versava sobre a proposta de introdução da 'prova de retenção' ${ }^{12}$ como rotina nos exames radiográficos do esôfago nas zonas endêmicas da doença de Chagas (LAUAR; OLIVEIRA; REZENDE, 1959). Em setembro do ano seguinte falou sobre a 'Forma digestiva da moléstia de Chagas' à Sociedade de Gastroenterologia e Nutrição de São Paulo, quando então lhe foi conferido o título de sócio correspondente nacional daquela sociedade. Reafirmando a necessidade de sua inclusão na sistemática da tripanossomíase, Rezende não se deteve no estudo dos megas, mas sim na sintomatologia "multiforme e mal definida" ligada ao aparelho digestivo, que em muitos casos levaria os pacientes a tratamentos inadequados (REZENDE, 1959, p. 223). Este trabalho foi comentado em uma publicação internacional, considerada obra de referência no meio médico, e ampliou a visibilidade destes médicos, como se verá a seguir.

\footnotetext{
${ }^{12}$ Consiste esta prova em obter duas radiografias sucessivas do esôfago com um intervalo mínimo de um minuto, sem nova ingestão de contraste. A permanência residual de contraste no terço inferior do esôfago sugere desordem motora do órgão e exige investigação sorológica para doença de Chagas (Lauar, Oliveira, Rezende, 1959, p. 102).
} 


\title{
Expandindo as fronteiras: as redes intelectuais além do Brasil Central
}

O trabalho apresentado por Rezende à Sociedade de Gastroenterologia e Nutrição de São Paulo, no qual reafirmava a necessidade de inclusão da forma digestiva na sistemática da doença de Chagas, foi resumido e comentado pelo gastroenterologista alemão Franz Ingelfinger no Year Book of Medicine de 1960-61 (BEESON et al, 1960-61a/b) ${ }^{13}$. Autoridade mundial em esôfago, atuante no Evans Memorial Hospital em Boston (TOY, 2002), Ingelfinger visitou o Brasil em 1959 durante o XI Congresso Brasileiro de Gastroenterologia, que se realizou em Belém. Convidado por Paula e Silva na qualidade de conferencista, visitou Goiânia e Ribeirão Preto após o congresso, onde tomou conhecimento dos trabalhos desenvolvidos pelos médicos locais sobre doença de Chagas (REZENDE, MENEGHELLI, 2001).

Antes disso, porém, Rezende já vinha se comunicando com Ingelfinger desde abril de 1958, quando enviou ao médico alemão algumas separatas sobre o megaesôfago endêmico no Brasil e a doença de Chagas. Reconhecido pelos trabalhos que desenvolvia sobre fisiopatologia do esôfago, Rezende pediu a Ingelfinger alguns artigos seus sobre o tema. Fascinado pelas pesquisas desenvolvidas pelos médicos do interior e manifestando o desejo de conhecer o Brasil e o trabalho que desenvolviam, Ingelfinger assim se manifestou:

\begin{abstract}
I am extremely grateful for the reprints you recently sent me as well as the long letter in which you so clearly summarized your remarkable experience with megaesophagus. You certainly present your views of this disease most lucidly and convicingly. In particular, I am quite ready to be convinced that megaesophagus is a syndrome in which the responsible neuromuscular mechanism can be damaged by different agents (...). (Carta remetida por Ingelfinger a Rezende, outubro de 1958). ${ }^{14}$
\end{abstract}

Um ano após o envio desta carta, como se viu, Ingelfinger concretizaria seu desejo de visitar o Brasil. Acompanhado por Câmara Lopes, do Departamento de Cirurgia da FMRP,

\footnotetext{
${ }^{13}$ Ingelfinger era um dos editores desta publicação que funcionava como obra de referência na qual eram resumidos os artigos médicos considerados mais significativos.

14 "Sou extremamente grato pelas separatas que me enviou recentemente assim como pela longa carta em que resume claramente sua notável experiência com o megaesôfago. Você certamente apresenta seus pontos de vista sobre a doença de forma mais lúcida e convincente. Em particular, estou completamente convencido de que o megaesôfago é uma síndrome em que o mecanismo neuromuscular responsável pode ser danificado por diferentes agentes" - tradução livre feita pelo autor.
} 
foi a Goiânia pronunciar uma conferência sobre motilidade esofagiana. No Hospital Rassi, examinou numerosos casos de megaesôfago, realizando em alguns pacientes o teste por ele idealizado do mecolil, ${ }^{15}$ e tomou conhecimento também de dados e observações clínicas dos médicos goianos, tendentes a demonstrar a relação etiológica existente entre doença de Chagas e megaesôfago.

De Goiânia, Ingelfinger seguiu para Ribeirão Preto, onde continuou suas observações sobre megaesôfago, notadamente sobre o tratamento cirúrgico (NOTICIÁRIO, 1959d). Nesta cidade permaneceu por alguns dias, transitando entre o Hospital das Clínicas, o Serviço de Radiologia e Departamentos de Parasitologia, Patologia e Clínica Médica da FMRP. Acompanhou cirurgias, como a idealizada por Câmara Lopes em que o esôfago do paciente é totalmente extirpado - a esofagectomia - utilizada em casos de 'mal de engasgo' de extrema gravidade (REZENDE; MENEGHELLI, 2001, p. 264), e teve também informações sobre a epidemiologia e a profilaxia da doença, se surpreendendo com a elevada prevalência do megaesôfago no Brasil Central. Suas impressões sobre a visita ficaram registradas na correspondência trocada com Rezende:

Of course I shall never forget the professional aspects of my visit to your pleasant city, for it was here that I first realized the magnitude of the problem of esophageal aperistalsis in your part of the world. Of course, I had heard about and read about it, and this was one of the reasons I was coming to Goiânia. Nevertheless, the actual experience far exceeded my anticipation (...). (Carta remetida por Ingelfinger a Rezende, novembro de 1959). ${ }^{16}$

Muito entusiasmado com tudo o que viu e aprendeu no interior do país, Ingelfinger sugeriu que Rezende publicasse suas pesquisas em revistas de circulação internacional e voltadas para um público mais amplo, bem como considerou a possibilidade de estreitar ainda mais os laços entre ambos os meios médicos:

If you ever plan to publish your remarkable observations in an american medical journal, I would certainly send it first to the American Journal of Medicine or to the New England Journal of Medicine. These journals have a much larger circulation and will reach a much larger audience than

\footnotetext{
${ }^{15}$ Trata-se de um tipo de teste para diagnóstico da acalasia no qual se injeta uma substância - o mecolil que faz o esôfago contrair quando está desnervado, indicando a doença (Cf. REZENDE, 2001, fita 04/lado B; REZENDE, MENEGHELLI, 2001).

16 “É claro que eu nunca esquecerei os aspectos profissionais da minha visita à sua agradável cidade, porque foi aí que eu me dei conta pela primeira vez da magnitude do problema da aperistalse esofágica em sua parte do mundo. É claro, eu já tinha ouvido e lido a respeito, e esta foi uma das razões pelas quais eu estive em Goiânia. No entanto, a experiência real superou minhas expectativas" - tradução livre feita pelo autor.
} 
Gastroenterology. In addition, if I can help you any way with the preparation of such manuscripts, i.e. in the way of english expressions and general style, please do not hesitate to call on me. I should like to help in any way I can. (...)My experience with esophageal disease in Goiânia and Ribeirão Preto has certainly changed my opinion, and I am now approaching the disease as we see it up here with new ideas, new enthusiasm, and much better orientation. For helping me attain these concepts, and for your great friendliness and kindness, please accept my heartfull thanks. I also trust that our meeting is just the beginning of future professional cooperation and friendship (...). (Carta remetida por Ingelfinger a Rezende, novembro de 1959). ${ }^{17}$

A aproximação entre os médicos do Brasil Central e o médico estrangeiro resultou em trocas intelectuais bastante significativas para ambos os lados. Por ocasião do VI Congresso Panamericano de Gastroenterologia, que se realizou em Nova lorque em abril de 1962, Köeberle, Câmara Lopes e Rezende receberam convite de Ingelfinger para irem a Boston visitar seu serviço no Evans Memorial Hospital e ali participar de um debate informal sobre a doença de Chagas e sistema digestivo. No mês seguinte participaram, ao lado de Paula e Silva, do II Congresso Mundial de Gastroenterologia, em Munique, sob a presidência do gastroenterologista Norbert Henning. ${ }^{18}$ Os primeiros trabalhos de âmbito internacional da carreira de Rezende foram publicados em decorrência de sua participação neste evento (REZENDE, 1963; REZENDE et al, 1963).

Fazia parte do programa deste congresso na Alemanha um simpósio sobre acalasia do esôfago, presidido por Ingelfinger e moderado por Paula e Silva. Segundo Rezende e Meneghelli (2001), a quantidade de brasileiros neste simpósio, superior a de outros países ali representados "devia-se, em parte, ao prestígio pessoal do Prof. Geraldo Siffert, e em parte, ao interesse despertado pela doença de Chagas como causa importante de uma modalidade de acalasia" (REZENDE; MENEGHELLI, 2001, p. 267). O reconhecimento do

\footnotetext{
17 "Se você já planeja publicar suas notáveis observações em um periódico médico americano, eu certamente o enviaria primeiro para o American Journal of Medicine ou para o New England Journal of Medicine. Estas revistas têm uma circulação muito maior e vão atingir um público mais amplo do que Gastroenterology. Além disso, se eu puder ajudá-lo com a preparação de tais manuscritos, por exemplo, na forma de expressões em inglês e estilo geral, por favor, não hesite em me chamar. Gostaria de ajudar em qualquer coisa que eu puder (...). Minha experiência com a doença de esôfago em Goiânia e Ribeirão Preto certamente mudou minha opinião, e agora estou abordando a doença a partir de novas ideias, novo entusiasmo e orientação muito melhor. Por me ajudar a atingir esses conceitos, e por sua simpatia e amabilidade, por favor, aceite meus agradecimentos. Eu também acredito que o nosso encontro é apenas o início de uma cooperação profissional futura e de amizade (...)" - tradução livre feita pelo autor.

${ }^{18}$ Norbert Henning havia estado no Brasil em 1961, inclusive em Goiânia, conhecia os trabalhos de Köeberle, e estava bem informado sobre a alta prevalência do megaesôfago em certas regiões do Brasil e sua associação com a doença de Chagas (REZENDE; MENEGHELLI, 2001).
} 
trabalho desenvolvido pelos médicos no interior do país neste congresso, teria, segundo afirma Rezende, levado os brasileiros a começarem a falar em 'megaesôfago chagásico' (Rezende, 2009). Segundo Rezende: "infelizmente a medicina brasileira passa a dar crédito às coisas de casa quando tem aceitação fora. Então a literatura médica fora do Brasil já começou a falar em megaesôfago chagásico. Os daqui tiveram que aceitar" (REZENDE, 2001, fita 04/lado B).

A circulação internacional das pesquisas dos médicos do interior, decorrente do contato com Ingelfinger, e a boa recepção às mesmas teriam, portanto, repercutido favoravelmente sobre a aceitação da etiologia chagásica dos megas, aumentando a credibilidade dos médicos do Brasil Central. A resistência interna teria colaborado para que a aceitação internacional precedesse a nacional, principalmente no que se refere aos meios científicos do Rio de Janeiro e São Paulo ${ }^{19}$ (REZENDE, MENEGHELLI, 2001, p. 266). Tal resistência fica evidente durante o I Congresso Internacional da Doença de Chagas, que aconteceu em julho de 1959 no Rio de Janeiro.

\section{Últimos muros de resistência à etiologia chagásica do megaesôfago}

Acontecimento marcante nos meios científicos nacional e internacional, o I Congresso Internacional da Doença de Chagas, organizado por Carlos Chagas Filho sob os auspícios do Instituto Oswaldo Cruz, contou com a participação de personalidades médicas do Brasil e do exterior, perfazendo um total de mais de 500 pessoas. Rezende havia participado da organização do evento a convite do próprio Chagas Filho (REZENDE, 2001, fita 03/lado A) e no congresso apresentou uma casuística elevada de pacientes acometidos por megaesôfago ${ }^{20}$ a partir da qual pretendia convencer a respeito da individualização da forma digestiva da doença de Chagas (KROPF, RASSI, 2009).

Neste congresso a doença de Chagas foi abordada segundo vários pontos de vista, desde o epidemiológico até o profilático, passando pela transmissão, agente etiológico, clínica, diagnóstico laboratorial, anatomia patológica e terapêutica. Com relação à clínica, aspecto que mais interessa por conta das pesquisas de Rezende, chamam a atenção alguns

\footnotetext{
${ }^{19}$ Um indício de que a aceitação internacional da etiologia chagásica dos megas veio antes da nacional, está no relatório do grupo de estudos sobre doença de Chagas da OMS de 1960, no qual a forma digestiva já aparece dentro de sua sintomatologia clínica (Organización Mundial de la Salud, 1960).

${ }^{20} \mathrm{O}$ trabalho 'Alterações do tubo digestivo na moléstia de Chagas. Considerações em torno de 506 casos de megaesôfago', apresentado por Rezende, foi publicado nos anais deste congresso em 1963 (Cf. Rezende, 1963a, p. 1407-1426).
} 
trabalhos que se referem diretamente ao problema do megaesôfago e sua relação com a doença de Chagas. Aristóteles Brasil, de Belo Horizonte, por exemplo, defendeu que a doença de Chagas seria a mais importante causa de megaesôfago no país; Aluízio Prata, por outro lado, considerou que este aspecto deveria ser "melhor estudado" (Noticiário, 1959a).

Intitulado 'Relação etiológica entre doença de Chagas e megaesôfago', o trabalho apresentado por Aluízio Prata (1959b, p. 1317-1336) chama a atenção pela grande quantidade de informações reunidas sobre o megaesôfago. Partindo de um breve histórico a respeito, afirmou que "ao lado do megaesôfago endêmico, que certamente tem etiologia única, deve existir no Brasil, conforme sucede em todas as partes do mundo, casos esporádicos da doença obedecendo a outros mecanismos etiológicos" (Prata, 1959b, p. 1318). Em seguida, comenta sobre a distribuição geográfica da enfermidade e suas relações com a doença de Chagas, alertando para o fato de que, se era possível afirmar que em todas as regiões onde comprovadamente era endêmico o megaesôfago existiria também a doença de Chagas, o inverso não seria verdadeiro:

Contudo, na falta de conhecimento mais perfeito da geografia do megaesôfago e embora reconhecendo que, até o momento, esta doença somente tem sido descrita sob a forma endêmica nas regiões em que existe a doença de Chagas, achamos que este fato, isoladamente, não representa elemento de todo convincente, podendo ser explicado por caprichosa coincidência (...) (Prata, 1959b, p. 1321).

Após enumerar os autores que detectaram a presença de megaesôfago em doentes chagásicos, entre eles Aristóteles Brasil, Joffre Rezende, Anis Rassi e Koeberle, e considerar expressivos os números apresentados, avaliava a necessidade de verificar melhor como se comportaria o esôfago, ao exame radiológico, em um número razoável de pacientes não chagásicos (Prata, 1959b, p. 1323). Por outro lado, sinalizava estar convencido da relação entre as duas enfermidades:

Chagas em seus estudos geniais emitiu as hipóteses de que o bócio e o megaesôfago poderiam ser causados pelo Trypanosoma cruzi. Defendeu a primeira delas com mais entusiasmo e os fatos não a confirmaram. Agora, a segunda está sendo submetida ao seu teste de sobrevivência. Etzel enfileirou argumentos que para muitos pareceram decisivos na filiação do megaesôfago à avitaminose B1. Estes dois episódios, o da tireoidite parasitária e o da avitaminose B1 como causa do megaesôfago, nos parece que têm servido de freio a qualquer raciocínio apressado quanto à causa do megaesôfago. Daí talvez a prudência com que vem sendo aceita, pelos investigadores brasileiros, a etiologia chagásica dos megas, apesar 
do peso dos fatos já acumulados. Acreditamos que os dados disponíveis são suficientes para mostrar as estreitas relações entre as duas entidades mórbidas (...) (Prata, 1959b: 1331 - grifo meu).

Jairo Ramos, considerado um dos "papas de São Paulo" por Rezende (2001, fita 04/lado A), alinhou dados favoráveis e contrários à etiologia chagásica dos megas em seu trabalho intitulado 'Doença de Chagas e acalásia':

A exposição que fizemos parece-nos situar a questão tal como atualmente se nos apresenta. Se de um lado existem indicações que nos orientam para admitir que a doença de Chagas é responsável pelos síndromes cardíaco e digestivo ou melhor, responsável pela miocardite e pelos distúrbios dos órgãos ocos musculares que se caracterizam pelo prefixo mega; de outro lado há argumentos que contrariam este ponto de vista e que parecem indicar concomitância de duas doenças com etiologia diferente (...) (Ramos, 1959, p. 1401).

Sem demonstrar um firme posicionamento, Ramos afirmou que "os recursos disponíveis nas várias regiões nas quais a endemia se apresenta mais intensa e onde mais comuns são os casos agudos encontrados, não têm permitido estudo mais completo" (Ramos, 1959, p. 1402). Hoel Sette, de Recife, não só aceitava a forma digestiva da doença de Chagas como também considerava definitivamente provada a etiologia chagásica da acalásia. Pesquisadores do Chile, entre eles Amador Neghme, contribuíram com estudo sobre a relação dos megas com a doença de Chagas, demonstrando também aceitação deste fato. Na mesa redonda realizada ao final do congresso, as opiniões predominantes teriam sido no sentido de aceitar-se a doença de Chagas como uma das causas do megaesôfago e do megacólon (Noticiário, 1959b, p. 475-476). Apesar da oposição enfrentada, vale destacar a medalha comemorativa do cinquentenário da descoberta da doença de Chagas concedida pelo IOC a Rezende por ocasião deste congresso. No mesmo ano receberia também medalha e diploma conferidos pela Universidade de Minas Gerais o que indica o respaldo de ambas as comunidades médicas às pesquisas desenvolvidas no Brasil Central.

Em suma, o que a análise vem demonstrando é que a resistência na aceitação da etiologia chagásica dos megas esteve relacionada ao embasamento essencialmente clínico desta hipótese, isto é, pautado pela sistematização acurada de informações decorrentes quase exclusivamente da observação. Buscando fortalecer suas pesquisas e reflexões, os médicos do interior, em especial os goianos, capitaneados por Joffre Rezende, buscaram estreitar os laços com meios médicos mais prestigiados e para os quais a doença de Chagas 
era um tema relevante. A rede estabelecida com o núcleo de Ribeirão Preto foi fundamental ao longo deste processo de convencimento, conforme buscou-se demonstrar.

Além do grupo paulista, os goianos também contaram com outros núcleos de apoio importantes, como por exemplo no Triângulo Mineiro, de onde partiram as primeiras observações favoráveis à associação comprovada mais tarde pelos goianos. No Rio de Janeiro podemos citar nomes de peso entre os aliados, como por exemplo, os médicos Paula e Silva e Chagas Filho, como se viu ao longo do trabalho. O Instituto Oswaldo Cruz também pode ser considerado um polo de apoio às pesquisas dos médicos do interior, na medida em que contribuía com a realização de sorologia. Magarinos Torres, médico que havia sido um grande colaborador de Carlos Chagas nas pesquisas sobre a tripanossomíase, e chefe da Divisão de Patologia deste instituto, assim se manifestou em carta pessoal endereçada a Rezende em agosto de 1959, logo após o congresso:

Sim, bastante aprendemos, todos nós, no recente Congresso, tão bem organizado e conduzido pelo Prof. Carlos Chagas Filho, com o concurso do IOC. O entusiasmo que tenho pela moderna geração de médicos do meu país, aqui nascidos e formados, os quais foram capazes de sobrepujar todas as dificuldades naturalmente encontradas longe dos grandes centros urbanos, para trabalharem de modo tão profícuo, e cujo melhor exemplo é o da Escola Goiana, cresceu nesse Congresso, vendo que estão despertando novos companheiros, já em outras regiões do Brasil (Pernambuco, Bahia). Minhas sinceras felicitações pela parte pessoal, de grande relevo, que vem desempenhando na ampliação dos conhecimentos sobre a doença de Chagas (...) (Carta enviada por Magarinos Torres a Rezende - 03/08/1959).

Ainda em 1959, Rezende se tornou fellow da Royal Society of Tropical Medicine and Hygiene e no bojo das comemorações em torno do cinquentenário da doença de Chagas, preparou um número da Revista Goiana de Medicina, da qual era editor, especialmente dedicado à doença nas Américas. Neste número pode contar com trabalhos de pesquisadores da Argentina, Chile, Uruguai, Paraguai, Bolívia, Peru, Equador, Costa Rica, Guatemala, México e Estados Unidos. ${ }^{21}$ Alguns deles, inclusive, entregaram o material a ele pessoalmente durante o Congresso Internacional da doença de Chagas, do qual muitos participaram. $\mathrm{O}$ aceite destes especialistas ao convite para publicação feito por Rezende é

\footnotetext{
${ }^{21}$ Estes especialistas eram Cecílio Romaña (Argentina), Amador Neghme e Jorge Román (Chile), Juan Osimani (Uruguai), Carlos J. Velázquez e Gustavo González ( Paraguai), Rafael Torrico (Bolívia), Aristides Herrer (Peru), José Rodriguez (Equador); Rodrigo Zeledón (Costa Rica), Romeo De León (Guatemala), Luiz Mazzotti (México) e Robert Yaeger (Estados Unidos).
} 
um indício importante de seu prestígio, bem como do reconhecimento ao trabalho que ele e seus pares desenvolviam na região.

Em âmbito nacional, Rezende considera o II Congresso Internacional de Proctologia, que aconteceu em São Paulo em 1960, como "último muro de resistência" à forma digestiva da doença de Chagas (REZENDE, 2001, fita 04/lado B). Neste evento houve uma mesa redonda sobre megacólon presidida por Alípio Corrêa Netto, da qual Rezende participou juntamente com Koeberle. Ao final, o cirurgião paulista Edmundo Vasconcelos defendeu a etiologia viral do megaesôfago e do megacólon, indo na contramão das pesquisas dos médicos do Brasil Central. Três anos depois, no entanto, no âmbito do XV Congresso Brasileiro de Gastroenterologia, realizado em Goiânia, os goianos foram homenageados pelo trabalho empreendido, conforme sintetizado na fala do médico paulista Daher Cutait. Em simpósio no qual se abordou o tema do megacólon, este especialista em cirurgia do aparelho digestivo abriu seus comentários exaltando os colegas

de Goiânia "pela sua enorme contribuição científica no avanço do conhecimento da moléstia de Chagas, e em particular do tema que vamos discutir" (CUTAIT, 1965, p. 228). Ao que tudo indica, ia chegando ao fim a tertúlia iniciada nos anos 40 e daí por diante o trabalho de Rezende, como síntese dos esforços de todos os médicos do interior do país que haviam investigado o tema, ganharia pleno reconhecimento, sendo considerado um marco na compreensão das formas clínicas da doença (PRATA, 1999).

\section{Considerações finais}

Como foi possível mapear, a trajetória intelectual de Rezende entre sua formatura na Faculdade Nacional de Medicina em 1950 e o ingresso como professor na Faculdade de Medicina de Goiás em 1960 esteve quase integralmente voltada para as pesquisas em torno da forma digestiva da doença de Chagas. A maioria dos eventos nos quais tomou parte e dos artigos que publicou demonstrou este movimento de Rezende em busca da comprovação do vínculo entre a tripanossomíase e o 'mal de engasgo'. A rede de relações que estabeleceu com médicos provenientes de outras instituições, em particular com aqueles que atuavam em Ribeirão Preto, se deu principalmente em função dos interesses comuns de pesquisa em torno da doença de Chagas. A forma com que conduziu suas pesquisas em Goiás e a qualidade de seu trabalho científico, embora não tenham sido suficientes para alcançar o reconhecimento de seus pares internamente em um primeiro momento, levaram Rezende a cruzar as fronteiras nacionais e ganhar notoriedade fora do 
Brasil, em países onde a enfermidade chagásica não era um problema de saúde pública e nos quais o megaesôfago possuía outra etiologia.

Ao despertar o interesse estrangeiro, a resistência oferecida pelos meios científicos mais tradicionais em solo pátrio arrefeceu. Por conta desta resistência, ou apesar dela, Rezende soube circular e conquistar aliados importantes, com destaque para o trabalho levado a cabo pelo patologista Köeberle - responsável por fornecer a prova anatomopatológica para as observações clínicas do colega goiano e dos demais médicos do interior. A partir de 1960, Rezende daria continuidade às suas pesquisas como chefe do Departamento de Clínica Médica da Faculdade de Medicina de Goiás. Munido de mais recursos no seio desta instituição e atuando no Hospital das Clínicas de Goiânia, Rezende viria a ser assessor da OMS e da OPAS para estudos sobre a tripanossomíase (Rezende, 2001) e incentivaria seus alunos a se aprofundarem sobre a doença "símbolo dos médicos do Brasil Central", segundo a historiadora Simone Kropf (2009, p. 480), e que permanece como um grave problema de saúde no Brasil.

\section{REFERÊNCIAS}

Arquivos Pessoais

Correspondência pessoal de Joffre Marcondes de Rezende: 1958-1960

Fontes orais

RASSI, Anis. Depoimento. Projeto História da Pesquisa sobre a Doença de Chagas no Brasil. Rio de Janeiro: Programa de História Oral da Casa de Oswaldo Cruz, 2001.

REZENDE, Joffre Marcondes de. Depoimento. Projeto História da Pesquisa sobre a Doença de Chagas no Brasil. Rio de Janeiro: Programa de História Oral da Casa de Oswaldo Cruz, 2001.

Fontes impressas

ANDRADE, Zilton. Anatomia patológica da Doença de Chagas. Revista Goiana de Medicina, Goiânia, v.04, n.2, p. 103-119, 1958.

BEESON, Paul B. et al. The Year Book of Medicine 1960-61. Chicago, 1960-61.

CHAGAS, Carlos. Tripanosomíase americana. Forma aguda da moléstia. Memórias do Instituto Oswaldo Cruz, Rio de Janeiro, v.08, n.37, p.69, 1916.

CUTAIT, Daher. Simpósio sobre Megacólon. Revista Goiana de Medicina, Goiânia, v.11, n. 3-4, p. 225-259, 1965. 
FREITAS, José L. Pedreira de. Comentário aos trabalhos apresentados ao $8^{\circ}$ Congresso Médico do Triângulo Mineiro e do Brasil Central sobre o tema: "Estado atual da Doença de Chagas em Goiás. Revista Goiana de Medicina, Goiânia, v.02, n.4, p. 315-320, 1956.

KÖEBERLE, Fritz. Patogênese dos “megas". Revista Goiana de Medicina, Goiânia, v.02, n. 2, p. 101-110, 1956.

LAUAR, Kemil; OLIVEIRA, Aluízio Ramos; REZENDE, Joffre M. de. Valor do tempo de esvaziamento esofagiano no diagnóstico da esofagopatia chagásica (prova de retenção). Revista Goiana de Medicina, Goiânia, v.05, n. 2, p. 97-102, 1959.

MINEIRO, Virgílio. Contribuição à etiologia do megaesôfago. Revista Goiana de Medicina, Goiânia, v.04, n.1, p. 29-34, 1958.

NEIVA, Arthur; PENNA, Belisário. Viagem Científica pelo Norte da Bahia, sudoeste de Pernambuco, sul do Piauí e de norte a sul de Goiás. Ed. Fac-similar. Brasília; Senado Federal, 1999.

NOTICIÁRIO. Revista Goiana de Medicina, Goiânia, v.05, n.2, p. 166-170, 1959a.

NOTICIÁRIO. Revista Goiana de Medicina, Goiânia, v.05, n.4, p. 471-480, 1959b.

ORGANIZACIÓN MUNDIAL DE SALUD. Serv. Inf. técn. - Enfermedad de Chagas: Informe de un Grupo de Estudio. Ginebra: OMS, 1960.

PAULA E SILVA, Geraldo Siffert. Formas digestivas na tripanossomíase americana. Revista Goiana de Medicina, Goiânia, v.04, n.1, p. 57-61, 1958.

PORTO, Calil. Gastropatia chagásica crônica - nota prévia. Revista Goiana de Medicina, Goiânia, v.01, n.1, p. 43-54, 1955.

PORTO, Celmo Celeno. História do megaesôfago nos Congressos Médicos do Brasil Central. Revista Goiana de Medicina, Goiânia, v.16, n. 1/2, p. 117-136, 1970.

PRATA, Aluízio. Prognóstico e Complicações da doença de Chagas. Revista Goiana de Medicina, Goiânia, v.05, n. 2, p. 87-96, 1959a.

Relação etiológica entre doença de Chagas e megaesôfago. Congresso Internacional sobre a doença de Chagas: resumos dos trabalhos apresentados. Rio de Janeiro, 1959b.

RAMOS, Jairo. Doença de Chagas e acalásia, Congresso Internacional sobre a doença de Chagas: resumos dos trabalhos apresentados. Rio de Janeiro, 1959.

RASSI, Anis et al. Fase aguda da Doença de Chagas - aspectos clínicos observados em 18 casos. Revista Goiana de Medicina, Goiânia, v.04, n. 2, p. 161-189, 1958.

REZENDE, Joffre M. Megaesôfago por Doença de Chagas. Revista Goiana de Medicina, Goiânia, v.02, n.4, p. 279-314, 1956.

Forma digestiva da moléstia de Chagas. Revista Goiana de Medicina, Goiânia, v.05, n.3, p. 193-227, 1959.

The endemic South American Megaesophagus. Clinical aspects of endemic megaesophagus. An. IInd World Congress of Gastroenterology. Vol. I, p. 69-74, Basel, S. Karger, 1963.

REZENDE, Joffre M. de.; RASSI, Anis. Comprometimento do esôfago na moléstia de Chagas. Megaesôfago e cardiopatia. O Hospital, Rio de Janeiro, v. 53, n.1, p. 1-15, 1958.

REZENDE, Joffre M. de. et al. Achalasia of esophagus - Panel discussion. An. Ilnd World Congress of Gastroenterology, Vol. I: 3-45, Basel, S. Karger, 1963.

REZENDE, Joffre M. de.; MENEGHELLI, U. G. A visita ao Brasil de Franz J. Ingelfinger e sua participação na divulgação dos conhecimentos sobre o megaesôfago chagásico. Revista da Associação Médica Brasileira, vol. 47 (3): 262-268, 2001. 
SILVEIRA, José Peixoto da. Saúde e educação. Goiânia: Oriente, 1981.

CARVALHEIRO, José da Rocha (org.) et al. Clássicos em Doença de Chagas: histórias e perspectivas. Rio de Janeiro: Editora Fiocruz, 2009.

Bibliografia

DIAS, João Carlos Pinto. Etiologia chagásica do megaesôfago chagásico no Brasil. Revista de Patologia Tropical, vol.30, n. 2, p. 135-142, jul-dez, 2001.

ETZEL, Eduardo. A singular história dos megas chagásicos. GED, v. 18, n.3, p. 105-109, 1999.

KROPF, Simone P. Doença de Chagas, doença do Brasil: ciência, saúde e nação, 1909-1962. Rio de Janeiro: Editora Fiocruz, 2009.

; RASSI, Anis. A pesquisa clínica no interior do Brasil: a etiologia chagásica do megaesôfago. In: CAVALHEIRO, José da Rocha (org.) et al. Clássicos em Doença de Chagas: histórias e perspectivas. Rio de Janeiro: Editora Fiocruz, 2009.

PRATA, Aluízio. Evolution of the Clinical and Epidemiological knowledge about Chagas Disease 90 years after its discovery. Memórias do Instituto Oswaldo Cruz, Rio de Janeiro, vol.94, (Suppl.I), p. 81-88, 1999.

REZENDE, Joffre M. Vertentes da Medicina. São Paulo: Giordano, 2001.

- Megaesôfago chagásico (mal de engasgo): dados históricos sobre o reconhecimento de sua etiologia. Gastroenterologia Contemporânea, v. 02, n.2, p. 06-15, 1998.

A viagem científica de Neiva e Penna: roteiro para os estudos das doenças do sertão. História, Ciências, Saúde - Manguinhos, Rio de Janeiro, v.16, supl.1, p. 265-288, 2009.

TOY, Jennifer. The Ingelfinger Rule: Franz Ingelfinger at the New England Journal of Medicine, 1967-1977. Science Editor, vol. 25, n. 06, p. 195-198, 2002. 